\title{
Primary cutaneous amelanotic melanoma and gastrointestinal stromal tumor in synchronous evolution*
}

\author{
Fernanda Teixeira Ortega ${ }^{1}$ (In memoriam) \\ Francine Milenkovich Belinetti ${ }^{3}$ \\ Bruna Tuma ${ }^{2}$
}

\author{
Rogério Nabor Kondo ${ }^{2}$ \\ Mariana Onuki Okamura ${ }^{3}$
}

DOI: http:/ / dx.doi.org/10.1590/abd1806-4841.20174520

\begin{abstract}
Gastrointestinal stromal tumor is rare digestive tract mesenchymal tumor, most often in the wall of the stomach. It is a benign neoplasm, but it can become malignant if not treated. We report a case of gastrointestinal stromal tumor that was discovered after abdominal ultrasonography during staging of a patient with primary cutaneous amelanotic melanoma. Mutation in the tyrosine kinase receptor could explain the development of two types of tumors in the same patient.
\end{abstract}

Keywords: Gastrointestinal stromal tumors; Melanoma; Receptor protein-tyrosine kinases

\section{INTRODUCTION}

Association of gastrointestinal stromal tumor (GIST) with other neoplasms of distinct histological origin is already well documented, including some reports of association with malignant melanoma (MM). ${ }^{1}$ Tyrosine kinase receptor (KIT) mutations have already been detected in melanoma. The same mutation was identified in approximately $80 \%$ of GIST cases, including with in vitro therapeutic testing, showing a good response to tyrosine kinase inhibitors. This medication shows excellent control in the treatment of this mesenchymal tumor. ${ }^{2}$ Most studies show a higher prevalence of KIT mutations in MMs located in mucosa and acral region, with approximately $15 \%$ and $16 \%$ of cases, respectively. Cutaneous MM has a low incidence of mutation in the tyrosine kinase receptor gene (around $9 \%$ ). ${ }^{3}$

To our knowledge, this is the first case reported in the literature of the synchronous existence of amelanotic melanoma (AM) and GIST. We report a patient who was diagnosed with AM and, during the tracing of metastatic lesions, an abdominal tumor was detected, asymptomatic, diagnosed as GIST after resection.

\section{CASE REPORT}

A 52-year-old male patient, white, had an erythematous plaque on the right arm, which appeared one year earlier and presented slow growth, with no associated symptoms (he denied gastrointestinal symptoms). The patient had previous history of acute myocardial infarction two years ago.
On physical examination, patient presented an erythematous plaque of approximately $2 \mathrm{~cm}$ in diameter in the upper third of the extensor aspect of the right arm (Figure 1) and had a palpable mass in the left hypochondrium, painless to palpation, without visceromegaly. There was also an absence of palpable lymph nodes.

Skin lesion biopsy showed extensive superficial melanoma with peritumoral lymphocytic infiltrate, Breslow $0.98 \mathrm{~mm}$, level of infiltration (Clark) III and mitotic index $1 \mathrm{~mm}^{2}$ (Figure 2). Melanoma was confirmed by immunohistochemistry, positive for protein S-100 and HMB 45 (Figure 3).

After the diagnosis, the lesion was excised with margins of $1 \mathrm{~cm}$, and complete removal was obtained, confirmed by pathology.

Computed tomography (CT) of the abdomen showed expansive lesion with heterogeneous soft tissue density with irregular borders and well defined limits, measuring $10 \times 6 \times 13 \mathrm{~cm}$, located in mesenteric adipose planes of the mesogastrium, establishing broad areas of contact with adjacent hollow viscera, displacing them (Figure 4).

Retroperitoneum tumor was excised with resection of contiguous organs (atypical gastrectomy - the posterior wall of the antrum and of the gastric body where there was tumor invasion were resected). During surgery, presence of ascites, peritoneal carcinomatosis, or hepatic tumor was not observed. In anatomopathological examination, presence of low-grade fusocellular neoplasia, infiltrating gastric wall, $13 \mathrm{~cm}$ in diameter, compatible with GIST, was

Received on 02.03.2015.

Approved by the Advisory Board and accepted for publication on 27.03.2015.

* Study conducted at Dermatology Service of the Hospital Universitário Regional do Norte do Paraná - Universidade Estadual de Londrina (UEL) - Londrina (PR), Brazil.

Financial support: none.

Conflict of interest: none.

Private clinic - Cascavel (PR), Brazil.

Dermatology Service of Hospital Universitário Regional do Norte do Paraná (HURNP) - Universidade Estadual de Londrina (UEL) - Londrina (PR), Brazil.

Private clinic - Londrina (PR), Brazil. 
observed. Positivity for CD117 markers - KIT and CD34 gene product - , hematopoietic cell antigen and pericytes was confirmed by immunohistochemistry (Figures 5 and 6). Treatment with imatinib mesylate was started and the follow-up of the patient, who had an excellent response to the use of the medication and did not present new complaints until the moment, was maintained.

\section{DISCUSSION}

GIST corresponds to less than $1 \%$ of tumors of the gastrointestinal tract and occurs in the stomach in $65 \%$ of cases. Usually asymptomatic, it originates from the mesenchymal stem cell of the

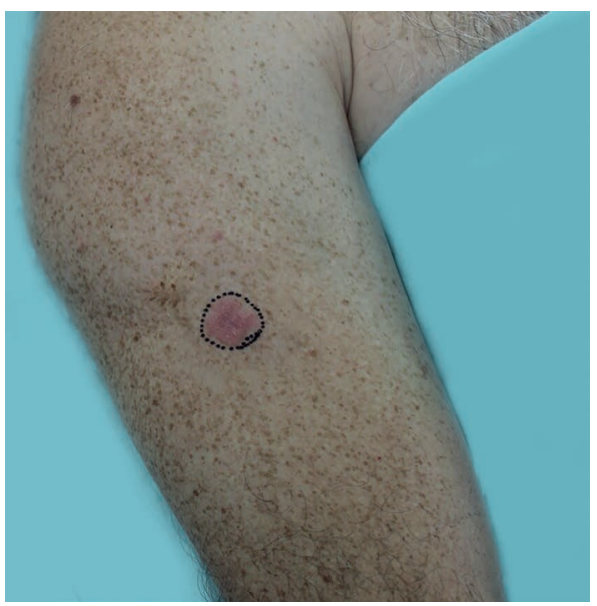

Figure 1:

Erythematous plaque in upper third of extensor aspect of right arm interstitial cells of Cajal. In $70 \%$ to $80 \%$ of cases, it is composed of spindle cells and, in $20 \%$ to $30 \%$, by epithelioid cells. ${ }^{1,4-7}$ Expression of CD117 by neoplastic cells in immunohistochemistry confirms the diagnosis of GIST. ${ }^{4}$ Activating mutations of KIT or PDGFRA genes are involved in the development of neoplasia. These genes encode homogeneous transmembrane receptors, sensitive to blockade with tyrosine kinase inhibitors, which are usually employed in the case of locally advanced disease, with no possibility of complete resection, metastatic disease, and high-risk GISTs for aggressive biological behavior, and the therapeutic response is dependent on the type of mutation found. ${ }^{3,5,8}$ Although several studies have documented the common synchronous or asynchronous coexistence of GIST with other independent malignancies, little is known about the significance and prognostic impact of its association with other neoplasms of different anatomical location and histogenetic derivation. ${ }^{1}$

Imatinib mesylate, a 2-phenyl-amino-pyrimidine derivative and selective BCR-ABL-tyrosine kinase inhibitor, was initially used for the treatment of chronic myeloid leukemia and subsequently for other neoplasms given its effectiveness in inhibiting other tyrosine kinases. Effectiveness of imatinib mesylate in GIST treatment was first described in 2001, which resulted in dramatic improvement in patients with multiple metastatic lesions. ${ }^{1,2}$

Amelanotic melanoma (AM) is a subtype of primary cutaneous MM that is difficult to diagnose and is defined as a lesion with no pigment at clinical observation. ${ }^{9,10}$ Its incidence is estimated to be between $1.8 \%$ and $8.1 \%$ of all MMs, including amelanotic and hypomelanotic in this percentage. Clinical presentation can be
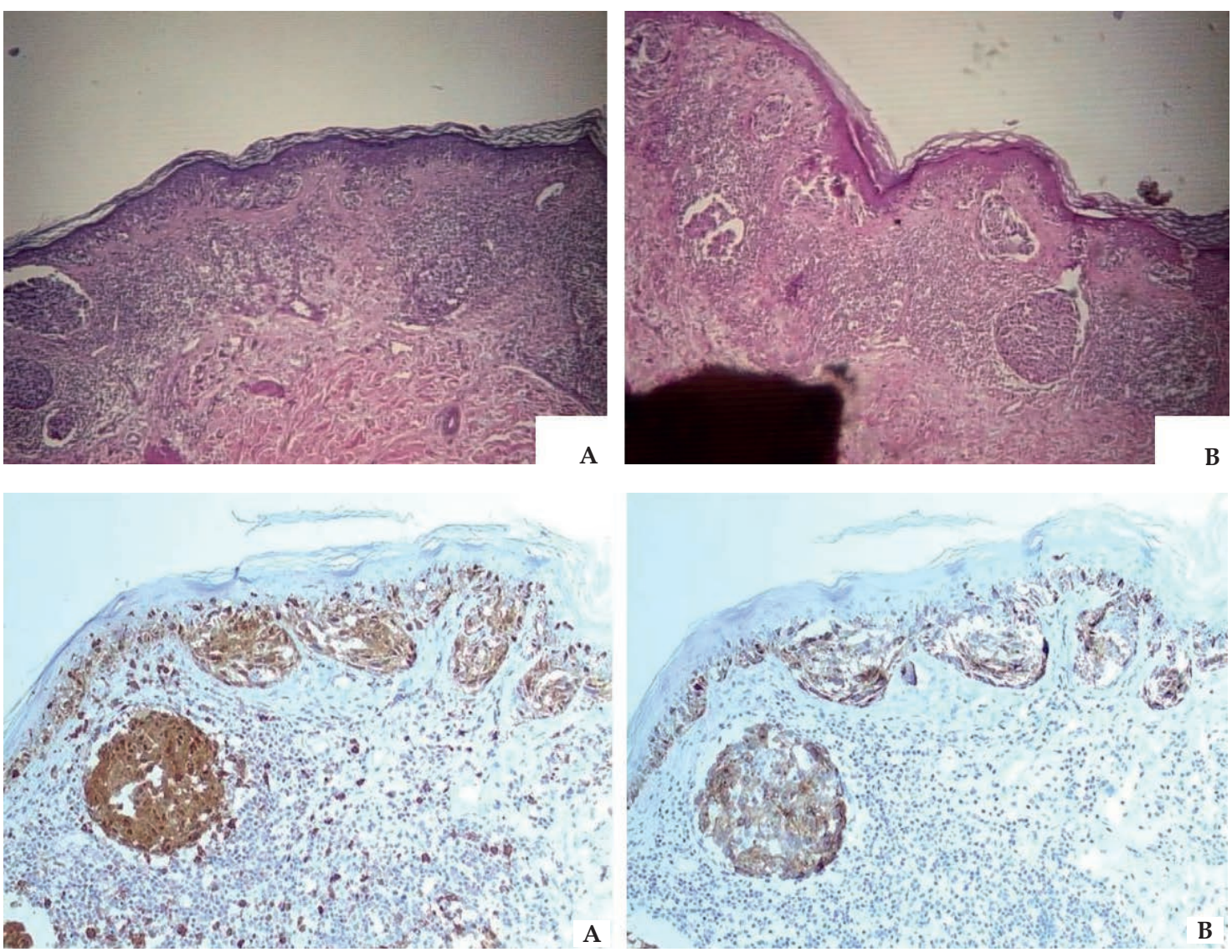

Figure 2:

Melanoma with peritumoral lymphocytic infiltrate with Breslow $0.98 \mathrm{~mm}$, level of infiltration (Clark) III and mitotic index $1 \mathrm{~mm}^{2}$ (Hematoxylin \& eosin, X40)
FigURE 3: Immunohistochemistry (X100) positive for protein S-100 (A) and for protein HMB 45 (B) 

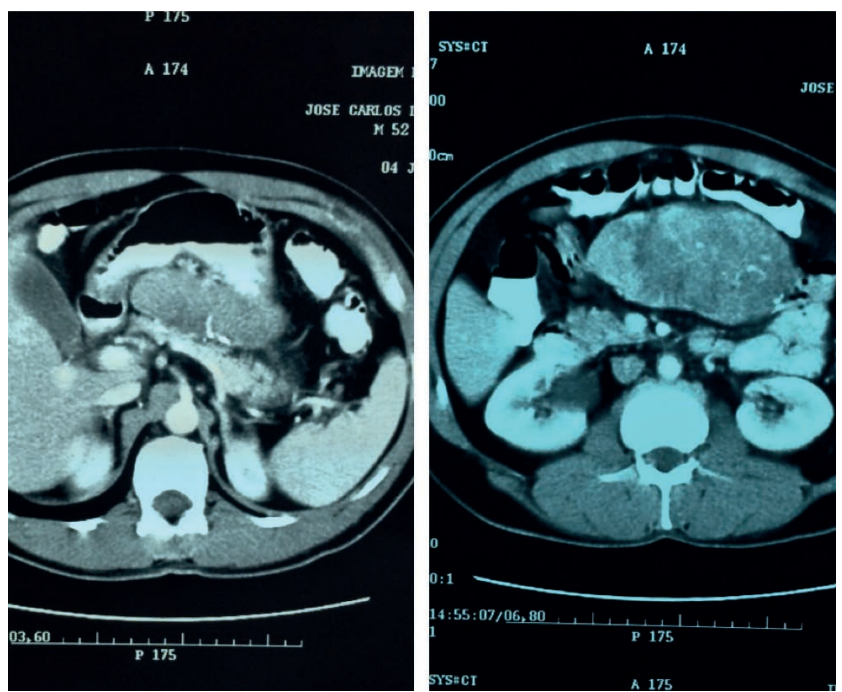

FIGURE 4: Computed tomography of the abdomen: expansive lesion with soft-tissue density, heterogeneous, with irregular margins and well-defined limits

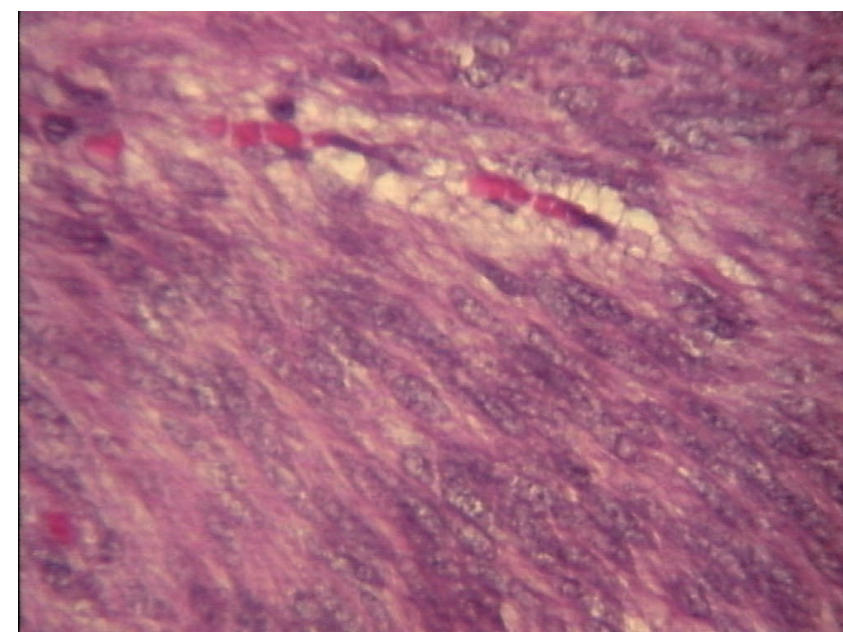

Figure 5: Anatomopathological examination of the abdominal tumor: low grade fusocellular neoplasia, infiltrating gastric wall, $13 \mathrm{~cm}$ in diameter, and absence of necrosis, compatible with GIST (Hematoxylin \& eosin, X400)

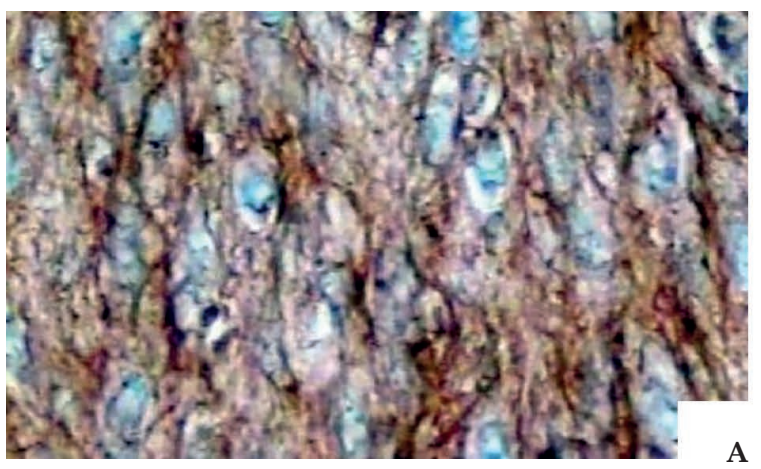

A

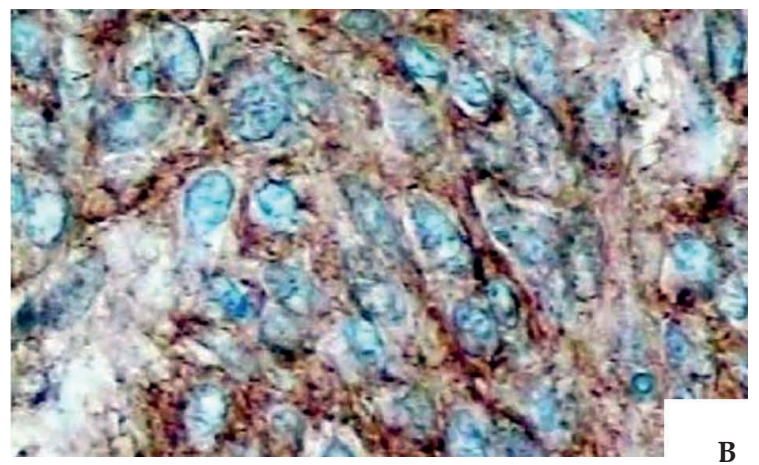

FIGURE 6:

Immunohistochemistry (X400): positivity for CD117 markers - KIT

(A) and CD34 gene product, hematopoietic cell antigen and B pericytes (B) classified into three types: erythematous macula on skin exposed to the sun, plaque without changes in skin color, and papulonodular lesion (which would be the most frequent form). The low amount of pigment is due to the deficiency of tyrosine enzyme or functional loss in melanin production and storage capacity caused by the rapid cellular differentiation. Prognosis is similar to that of MM, when compared with the same Breslow index, but it is frequently diagnosed later, which worsens the prognosis most of the time. ${ }^{9}$ Differential diagnoses include benign, pre-malignant or malignant diseases and the main differential diagnoses are common melanocytic nevi and basal cell carcinoma. ${ }^{9}$
Emerging target therapy is very promising for patients with $\mathrm{MM}$, since many mutations have been discovered in melanoma and molecules specifically inhibiting these mutations, as in the case of KIT and BRAF, are already being tested with promising future. , $^{910}$

We emphasize the importance and the need for new research to clarify the true prevalence and clinical significance of c-KIT gene mutation in melanomas, since target therapy would be an important treatment tool and could modify prognosis of this neoplasm that is so aggressive that is becoming increasingly common in the world. $\square$ 


\section{REFERENCES}

1. Nagai K, Matsumura Y, Nomura J, Inui M, Tagawa T. A case of double cancer involving oral malignant melanoma and gastrointestinal stromal tumor (GIST). Int J Oral Maxillofac Surg. 2005;34:328-30.

2. Antonescu CR, Busam KJ, Francone TD, Wong GC, Guo T, Agaram NP, et al. L576P KIT mutation in anal melanomas correlates with KIT protein expression and is sensitive to specific kinase inhibition. Int J Cancer. 2007;121:257-64.

3. Chi-Yuan T, Yu-Hung W, Chin-Yuan T. Characterization of KIT mutation in melanoma. Dermatol Sin. 2014;32:1-7.

4. Cai N, Morgenstern N, Wasserman P. A case of omental gastrointestinal stromal tumor and association with history of melanoma. Diagn Cytopathol. 2003;28:342-4.

5. Maeyama H, Hidaka E, Ota H, Minami S, Kajiyama M, Kuraishi A, et al. Familial gastrointestinal stromal tumor with hyperpigmentation : association with a germline mutation of the c-kit gene. Gastroenterology. 2001;120:210-5.

6. Guimaraes DP, Braggio E, Bacchi CE, Lopes LF, Small IA , Valadão CM, et al. Clinical and morphological characterization of GIST patients ( pts ) in Brazil. J Clin Oncol . 2004:22:4178.

7. Rubin BP, Heinrich MC, Corless CL. Gastrointestinal stromal tumour. Lancet. 2007;369:1731-41.

8. Lopes LF, Ojopi EB, Bacchi CE. Gastrointestinal stromal tumor in Brazil: Clinicopathology, immunohistochemistry, and molecular genetics of 513 cases. Pathol Int. 2008:58:344-52.

9. Fong ZV, Tanabe KK. Comparison of melanoma guidelines in the U.S.A., Canada, Europe, Australia and New Zealand: a critical appraisal and comprehensive review. Br J Dermatol. 2014;170:20-30.

10. Foletto MC, Haas SE. Cutaneous melanoma: new advances in treatment. An Bras Dermatol. 2014;89:301-10.
MAILING ADDRESS:

Rogério Nabor Kondo

Av. Ayrton Senna da Silva, 1055 - sala 1205

Gleba Palhano

86050-460 Londrina, PR

Email:kondo.dermato@gmail.com

How to cite this article: Ortega FT, Kondo RN, Belinetti FM, Okamura MO, Tuma B. Primary cutaneous amelanotic melanoma and gastrointestinal stromal tumor in synchronous evolution. An Bras Dermatol. 2017;92(5):707-10. 